\title{
Pediatric unplanned extubation: Process fail or adverse event?
}

\author{
Valeria C Neves, Camila G Ribas*, Adriana Koliski and José E Carreiro \\ Complexo Hospital de Clínicas da Universidade Federal do Paraná, Brazil
}

\begin{abstract}
Endotracheal intubation is one of the most common invasive procedures in routine paediatric intensive care. Unplanned extubation occurs when an endotracheal tube is inadvertently removed, leading to a "loss of control" in a highly controlled environment.
\end{abstract}

\section{Commentary}

Unplanned extubation (UPE) is the unintentional removal of a patient's breathing tube, either by self extubation or unplanned removal due to an external force that causes the tube to become dislodged and constitutes an adverse event $[1,2]$.

These events commonly occur in the hospital with financial impacts. The consequences associated with such events are respiratory failure, airway injuries, longer use of mechanical ventilation, increased length of stay in the PICU and longer hospitalization. In addition, there may be an increased risk of hypoxemia, atelectasis and susceptibility to ventilator associated pneumonia [3-6].

The risk factors associated with these adverse events observed were non-compliance with the protocols, as well as lack of innovative and adaptive strategies for quality control. Studies frequently describe weaning off $\mathrm{MV}$ as a potential risk factor for UPE because the withdrawal of sedation causes psychomotor agitation $[1,2,6]$. The lack of well-established weaning protocols in paediatrics prolongs the patient's time on mechanical ventilation favours the high incidence of UPE [2,7].

However, it is observed that, in practice, UPE occur during the first days of mechanical ventilation, when patients are in controlled ventilation mode and receive sedation. This would suggest that UPE probably occurred during team handling, but also that sedation was insufficient, leading to excessive agitation during patient handling [813].

The UPE is more common among patients under 12 months of age and one factor associated with UPE in paediatric patients is the size of the child, as infants have a smaller body surface on which the tube can be secured. Furthermore, these patients frequently present with excessive secretions and psychomotor agitation $[14,15]$.

Various studies have reported high reintubation rates. The main causes of reintubation are related to hypoxemia, excessive secretion and hypoventilation $[8,9]$. Another important impact of unplanned extubation in children is the trauma of reintubation requiring tracheostomies [7-15].

The strategic plan for UPE reduction should start from hospital administrative management by supporting and promoting local leadership in the intensive care unit with the aim of risk management and the safety of children in the intensive care unit. Interventions based on a multidisciplinary approach must been encouraged to reduce UPE rates. It is crucial to identify patients at potential risk and develop effective low-cost, easily implemented interventions so that the quality of care provided for intubated children can be improved [1,2,7,13-15].

Therefore, to review each incident related to the adverse event, it is necessary to determine the root cause, thus correcting the possible process failures. This action will have an impact on reducing the number of UPE.

\section{References}

1. Rachman BR, Watson R, Woods N, Mink RB (2009) Reducing unplanned extubation in a pediatric intensive care unit: a systematic approach. Int J Pediatr 1-5. [Crossref]

2. 2 Silva PSL, Reias ME, Aguiar VE, Fonseca MCM (2012) Unplanned extubation in the Neonatal ICU: A systematic review critical appraisal, and evidence-based recommendation. Respir care 58: 1237-1245. [Crossref]

3. Fernandes HS, Júnior SAP, Filho RC (2010) Qualidade em terapia intensiva. Rev Bras Clin Med 8: 37-45.

4. Alves MVMFF, Bissiguini PO, Nitsche MJT (2014) Profile of patients admitted in a pediatric intensive care unit of a hospital school in the countryside of São Paulo. Cienc Cuid Saude 13: 294-301.

5. Cheifetz IM (2013) Advances in monitoring and management of pediatric acute lung injury. Pediatr Clin N Am 60: 621-639. [Crossref]

6. Razavi SS, Nejad RA, Mohajerani AS, Talebian M (2013) Risk factors of unplanned extubation in pediatric intensive care unit. Tanaffos 12: 11-16. [Crossref]

7. Silva PSL, Farah D, Fonseca MCM (2017) Revisiting unplanned extubation in the pediatric intensive care unit: What's new? Heart \& Lung 46: 444-451. [Crossref]

8. Sadowski R, Dechert RE, Bandy KP (2004) Continuous quality improvement: reducing unplanned extubations in a pediatric intensive care unit. Pediatrics 114: 628-632. [Crossref]

${ }^{*}$ Correspondence to: Camila G Ribas, Complexo Hospital de Clínicas da Universidade Federal do Paraná, Brazil, E-mail: camilagemin@hotmail.com

Received: September 05, 2019; Accepted: September 23, 2019; Published: September 27, 2019 
9. Fitzgerald RK, Davis AT, Hanson SJ (2015) Multicenter analysis of the factors associated with unplanned extubation in the PICU. Pediatr Crit Care Med 16: 217 223. [Crossref]

10. Tripathi S, Nunez DJ, Katyal C, Ushay HM (2015) Plan to have No unplanned: a collaborative, hospital-based quality-improvement project to reduce the rate of unplanned extubations in the pediatric ICU. Respir Care 60: 1105-1112. [Crossref]

11. Kanthimathinathan HK, Durward A, Nyman A, Murdoch IA, Tibby SM (2015) Unplanned extubation in a paediatric intensive care unit: prospective cohort study. Intensive Care Med 41: 1299-1306. [Crossref]
12. Meregalli CN, Jorro Baron FA, D’Alessandro MA, Danzi EP, Debaisi GE (2013) Impact of a quality improvement intervention on the incidence of unplanned extubations in a Pediatric Intensive Care Unit. Arch Argent Pediatr 111: 391-397. [Crossref]

13. Menon K, Dundon B, Twolan BL, AlShammari S (2015) Approach to unplanned extubations in a pediatric intensive care unit. Can J Crit Care Nurs 26: 25-29. [Crossref]

14. Razavi SS, Nejad RA (2013) Risk factors of unplanned extubation in pediatric intensive care unit Tanaffos 12: 11-16. [Crossref]

15. Mehta NM, Sharma S, Laussen PC (2015) Unplanned extubation: securing the tool of our trade. Intensive Care Med 41: 1983-1985. [Crossref]

Copyright: $\odot 2019$ Neves VC. This is an open-access article distributed under the terms of the Creative Commons Attribution License, which permits unrestricted use, distribution, and reproduction in any medium, provided the original author and source are credited. 